\title{
Coping with unintended pregnancies: Narratives from adolescents in Nairobi's slums
}

Joyce Mumah

Caroline W. Kabiru

Chimaraoke O. Izugbara

Carol Mukiira

Follow this and additional works at: https://knowledgecommons.popcouncil.org/departments_sbsr-rh

Part of the Demography, Population, and Ecology Commons, Family, Life Course, and Society Commons, Inequality and Stratification Commons, International Public Health Commons, Maternal and Child Health Commons, and the Women's Health Commons How does access to this work benefit you? Let us know!

\section{Recommended Citation}

Mumah, Joyce, Caroline W. Kabiru, Chimaraoke O. Izugbara, and Carol Mukiira. 2014. "Coping with unintended pregnancies: Narratives from adolescents in Nairobi's slums," STEP UP Research Report. Nairobi: African Population and Health Research Center. 


\section{STEP SUP}

STRENGTHENING EVIDENCE FOR PRORAMMING ON UNINTENDED
KENYA

RESEARCH

REPORT

April 2014

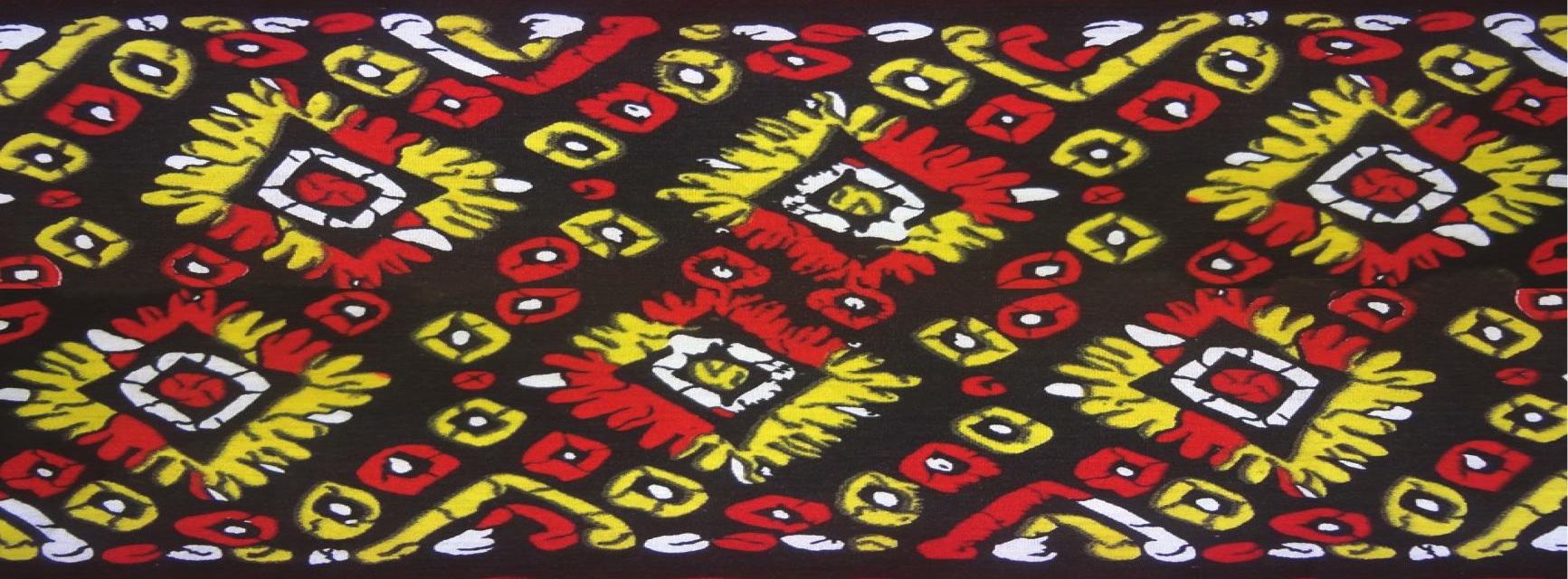

Coping with Unintended

Pregnancies: Narratives

from Adolescents in

Nairobi's Slums

JOYCE MUMAH, CAROLINE W. KABIRU, CHIMARAOKE IZUGBARA AND CAROL MUKIIRA 



\section{Coping with Unintended Pregnancies: Narratives from Adolescents in Nairobi's Slums}

JOYCE MUMAH, CAROLINE W. KABIRU, CHIMARAOKE IZUGBARA AND CAROL MUKIIRA

African Population and Health Research Center

STEP UP RESEARCH REPORT

April 2014
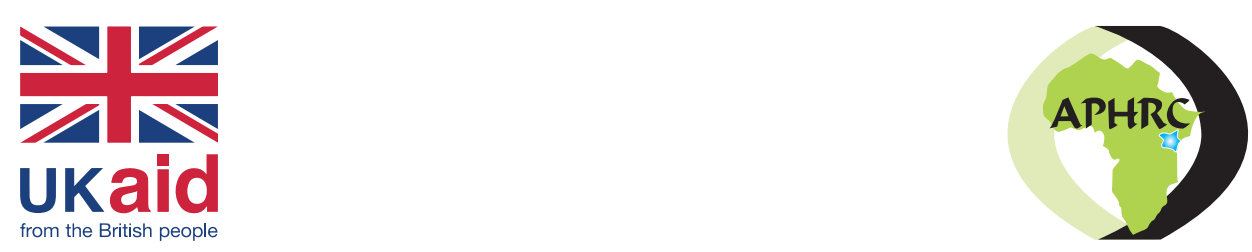
The STEP UP (Strengthening Evidence for Programming on Unintended Pregnancy) Research Programme Consortium generates policy-relevant research to promote an evidence-based approach for improving access to family planning and safe abortion. STEP UP focuses its activities in five countries: Bangladesh, Ghana, India, Kenya and Senegal. STEP UP is coordinated by the Population Council in partnership with the African Population and Health Research Center; icddr,b; the London School of Hygiene and Tropical Medicine; Marie Stopes International; and Partners in Population and Development. STEP UP is funded by UK aid from the UK Government. www.stepup. popcouncil.org

\section{APHRC AFRICAN POPULATION AND HEALTH RESEARCH CENTER}

The African Population and Health Research Center, Inc. (APHRC) is an international non-profit, research institute with headquarters in Nairobi, Kenya. APHRC's mission is to be a global center of excellence, consistently generating and delivering relevant scientific evidence for policy and action on population, health, and education in Africa. APHRC brings together a multi-disciplinary team of African scholars to lead the development of priority research programs and enhance the use of research findings for policy formulation and program improvement in sub-Saharan Africa. The Center was established in 1995 as a program of the Population Council and became an autonomous research institution in 2001. www.aphrc.org.

Suggested citation: Mumah, J, Kabiru, CW, Izugbara, C., and Mukiira, C. 2014. "Coping with unintended pregnancies: Narratives from adolescents in Nairobi's slums" STEP UP Research Report Nairobi: African Population and Health Research Center.

(c) 2014 African Population and Health Research Center Inc.

Please address any inquiries about STEP UP to the RPC co-directors:

Dr. Harriet Birungi, hbirungi@popcouncil.org

Dr. lan Askew, iaskew@popcouncil.org

Funded by

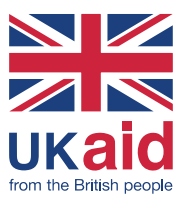




\section{Contents}

Acknowledgements …….................................................................... iv

List of Abbreviations ........................................................................... V

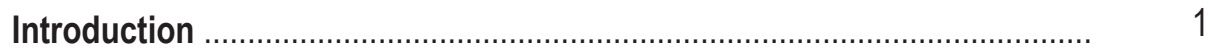

Sexual and reproductive health among the urban poor .......................... 1

Study objectives ..............................................................................

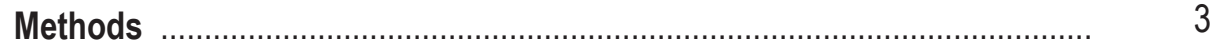

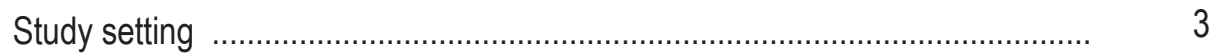

The everyday lives of young people in urban poor communities ...................... 3

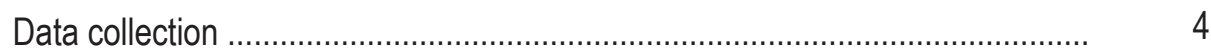

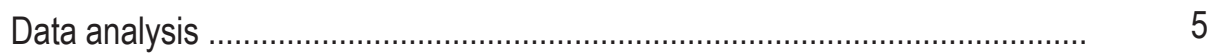

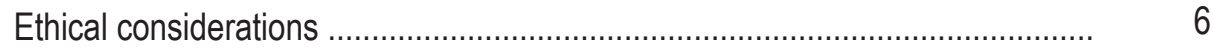

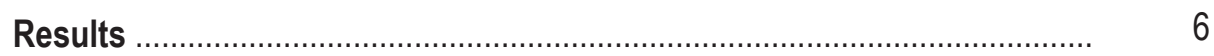

Narratives of socio-economic and health challenges ........................................ 6

Causes and consequences of unintended pregnancies ................................... 8

Coping with unintended pregnancies .............................................................. 11

Strategies to prevent unintended pregnancies ................................................... 14

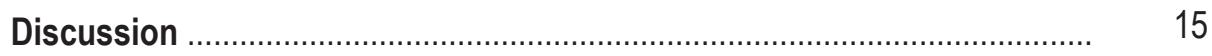

Programmatic Implications ................................................................... 17

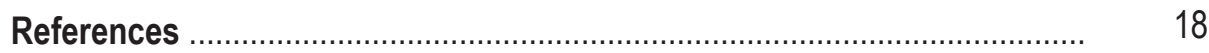




\section{Acknowledgements}

This report was prepared by Joyce Mumah, Caroline Kabiru, Chimaraoke Izugbara and Carol Mukiira under the Strengthening Evidence for Programming on Unintended Pregnancy (STEP UP) Research Programme Consortium, funded by UKaid from the Department for International Development. The authors thank Dr. Jean-Christophe Fotso, formerly of the African Population and Health Research Center, for his contributions to the STEP UP project, and we acknowledge tremendous inputs given during the development of the report from our external reviewers: Chi-Chi Undie, Nancy Termini, Harriet Birungi, Selina Esantsi, Fauzia Huda, Francis Obare and Anisuddin Ahmed.

Analysis and writing time for Joyce Mumah, Caroline Kabiru, Chimaraoke Izugbara and Carol Mukiira, was supported by funding from the STEP UP project (Grant SR1109D-6), Gates Urban Health Project through a grant from the Bill and Melinda Gates Foundation (Grant OPP1021893) and general support grants to APHRC from Sida (Grant Number 2011-001578), and the William and Flora Hewlett Foundation (Grant Number 2012-7612). 


\section{List of Abbreviations}

$\begin{array}{ll}\text { APHRC } & \text { African Population and Health Research Center } \\ \text { CHW } & \text { Community Health Worker } \\ \text { CPR } & \text { Contraceptive Prevalence Rate } \\ \text { FAWE } & \text { Forum for African Women Educationalists } \\ \text { FGD } & \text { Focus Group Discussion } \\ \text { FSE } & \text { Free Secondary Education } \\ \text { IDI } & \text { In-depth Interview } \\ \text { KDHS } & \text { Kenya Demographic and Health Survey } \\ \text { MOE } & \text { Ministry of Education } \\ \text { NUHDSS } & \text { Nairobi Urban Health and Demographic Surveillance System } \\ \text { SRH } & \text { Sexual and Reproductive Health } \\ \text { STI } & \text { Sexually Transmitted Disease } \\ \text { VCT } & \text { Voluntary Counseling and Testing }\end{array}$




\section{Introduction}

In Kenya, an estimated $43 \%$ of births among women aged $15-49$ years are unintended [1]. The high level of unintended pregnancy in Kenya is associated with low contraceptive use among women and girls. Among currently married and sexually active unmarried women aged 15-49 years, contraceptive prevalence rate (CPR) for modern methods is estimated at $28 \%$. Among sexually active $15-19$ year olds, the CPR is $16 \%$ [2].

Early sexual initiation exposes young people to greater risk of unintended pregnancies. The 2008/09 Kenya Demographic and Health Survey (KDHS) showed that the prevalence of unintended pregnancy among girls aged $15-19$ years is $47 \%$ [1]. Unintended pregnancies have major long-term health and socio-economic implications for women and girls and constitutes a major barrier to achieving progress in sexual and reproductive health (SRH) in the country. Annually, unintended pregnancies cause several thousands of girls - about 13,000- to drop out of school in Kenya [3]. Low educational attainment and early marriage owing to unintended pregnancy limit women's economic potential. A major consequence of unintended pregnancy in Kenya is unsafe abortion, which is a leading cause of maternal mortality and morbidity in the country [4]. A recent study found that nearly half a million induced abortions occurred in Kenya in 2012 [5]. The study established an abortion rate of 48 per 1000 women aged $15-49$ years. While comparable to Uganda, the abortion rate in Kenya was higher than the average for East Africa, which stands at 39 per 1000 women of reproductive age. The study also showed that about 120,000 women sought care for abortion-related complications in health facilities in 2012, with women below the age of 19 years accounting for $17 \%$ of all women seeking post-abortion care services and about $45 \%$ of severe abortion-related admissions in Kenyan hospitals [5]. An estimated $57 \%$ of abortions in Nairobi, capital city of Kenya, are among poor women [6].

\section{Sexual and reproductive health among the urban poor}

As in many parts of Africa, Kenya's urban population continues to grow. However, infrastructural development, housing, service provision and employment opportunities have not kept pace with rapid urbanization and growth of urban populations in Kenya. Consequently, majority of urban residents in Kenya live in poor informal settlements often referred to as slums. In Kenya, young people aged 10-24 years constitute a considerable proportion of urban slum residents (approximately $30 \%$ of the total population). These young people face particularly unique challenges as they transition to adulthood. They are often at risk of extreme poverty, poor schooling outcomes, early marriage, illiteracy, sexual and gender-based violence, and lack of access to essential services and amenities $[7,8]$.

Research shows that people living in slums are at greater risk for early childbearing, and other adverse sexual and reproductive health outcomes compared with their nonslums counterparts [9]. Slum-based adolescents engage in sexual activity earlier and are more likely to report transactional sex, unprotected sex, and multiple sexual partnerships compared with adolescents living in non-slum areas $[7,9,10]$. For example, by the age of $16,40 \%$ of adolescent girls in Kenyan slums were sexually-experienced compared to $20 \%$ of their counterparts in the general population [7]. The median age at first sexual activity 
among girls in the slums was 16.3 and 17.4 for girls in the general population [7]. Further, a recent study showed that only $29 \%$ of boys and $26 \%$ of girls between the ages of $12-22$ years in Nairobi's slum settlements used condoms during their first sexual experience [8]. Similar proportions were observed for condom use during the most recent sexual intercourse.

Adolescent women living in poor slum settlements are also at higher risks for both unintended pregnancy and premarital childbearing than their non-slum counterparts. One study shows that $37 \%$ of girls aged $15-22$ years in two Nairobi slums had experienced an unwanted pregnancy [8]. When the sample is limited to sexually experienced girls, this proportion increases to $62 \%$. In the same study, girls reporting unwanted pregnancies were more likely to be out of school, to be married and to have lower educational attainment [8]. The consequences of unintended pregnancy are more severe among women under the age of 20. During pregnancy and the period surrounding it, adolescent girls are more likely to die from pregnancy related causes than women aged 20 years and above. Further, under-5 mortality and morbidity, stunting, malnutrition and underweight are higher among the first children of girls aged 12-20 years compared with those of women aged 24-26 years old [11].

\section{Study objectives}

The health and other risks associated with early pregnancy and sexual activity raise urgent need for appropriate interventions and programs to address adolescent reproductive behaviors. It is important to understand the circumstances surrounding, and factors associated with unintended pregnancies among young people, the challenges that limit their ability to protect their sexual and reproductive health, and how they deal with the outcomes of unintended pregnancy. While previous research has highlighted the high vulnerability of young slum residents to unintended pregnancies and associated poor health and socioeconomic outcomes, their strategies and practices for managing the consequences of unintended pregnancy have received little attention. The current formative study addresses this evidence gap and focuses on the management of unintended pregnancy among adolescents living in resource poor settings. Our study aimed to answer the following questions: What are the unintended pregnancy-related experiences of adolescents in urban poor communities in Kenya? Secondly, how do these adolescents manage the consequences of unintended pregnancy?

The experience of an unintended pregnancy leads to two primary responses; carrying the pregnancy to term or termination of the pregnancy. The goal of the current formative study is to understand how young people make decisions and deal with the consequences of an unintended pregnancy. Study findings are expected to inform the design and delivery of SRH intervention programs to meet the unique needs of adolescents living in resource poor urban settings. 


\section{Methods}

\section{Study setting}

The formative research project was implemented in Nairobi, Kenya between January and February, 2013. The study was nested within APHRC's Nairobi Urban Health and Demographic Surveillance System (NUHDSS), which is located in Korogocho and Viwandani slum settlements. As of December 2012, the NUHDSS covered approximately 66,000 people in about 27,000 households. During the same period, there were about 3,800 adolescents aged 15-19 years in the demographic surveillance area. Both settlements are characterized by high levels of crime, insecurity, unemployment, sub-standard and overcrowded housing, limited educational opportunities and lack of social services and infrastructure.

\section{The everyday lives of young people in urban poor communities}

According to a study among young people in Korogocho and Viwandani conducted from 2007-2010 (Table 1), a typical adolescent aged 15-19 years in the two urban slums is likely to be in school and unmarried. However, young women relative to their male counterparts are more likely to be married and to be mothers, and less likely to be in school or living independently. Seven out of every 10 adolescents in urban slums are involved in extracurricular activities such as sports club, boy/girls club or a health club. In addition, 3 out of every 10 young people volunteer in their community. A greater proportion of males than females are members of a club, civic group or do volunteer work.

\begin{tabular}{|lccc|}
$\begin{array}{l}\text { Table 1: Socio-demographic characteristics of adolescents aged } \\
\text { survey Transitions to Adulthood Study }\end{array}$ 2007-2010 & years, baseline \\
\hline & $\mathrm{n}=937$ & $\mathrm{n}=907$ & $\mathrm{~N}=1844$ \\
\hline In school & $\%$ & $\%$ & $\%$ \\
\hline Married & 60.9 & 51.2 & $\mathbf{5 6 . 1}$ \\
\hline Has a child & 2.1 & 13.6 & 7.8 \\
\hline Owns/rents own home & 1.9 & 15.7 & 8.7 \\
\hline Is a member of a club or civic group & 19.6 & 8.9 & 14.4 \\
\hline Volunteers & 76.6 & 67.7 & 72.2 \\
\hline
\end{tabular}

Although the odds of transiting to secondary school among slum-dwelling adolescents are relatively low, close to $90 \%$ of $15-19$ year olds believe that completing secondary school and going to university is very important. However, only $50 \%$ believe that their chances of actually 
completing secondary school are high, while only $25 \%$ believe that their chances of joining university are high. In the same age group, about $30 \%$ report that their family or household did not have enough food to feed everyone, and about $40 \%$ report that their family or household suffered because their parent or guardian was out of a job.

With respect to delinquent behaviors, almost 1 in every 2 adolescents aged 15-19 years in the slums have never engaged in behavior such as fighting, carrying weapons or selling alcohol. However, young people growing up in the slums make the transition to first sex much earlier than their peers in non-slum areas [12]. Further, the study data show that the likelihood of deviant behavior is high as these adolescents' aspirations often exceed their perceived expectations for achieving their goals [13]. Overall, the average young person in Nairobi's slums has hopes and dreams like other young people their age and most are pro-socially engaged; however, as they grow older in situ, their hopes begin to fade as the realities of a restrictive local environment begin to take their toll [13].

\section{Data collection}

Data were collected using semi-structured in-depth interview (IDI) and focus group discussion (FGD) guides.

The guides were designed by an international team of researchers with extensive research experience in adolescent health as well as sexual and reproductive health in resource-poor urban settings. Interview questions primarily sought information on respondents' personal experiences with, as well general knowledge about, sexuality, unintended pregnancies and abortion. The tools were developed in English and translated into Swahili, the common language used in the study area, by a bilingual researcher. The English and Swahili tools were reviewed by the research team and field interviewers to ensure consistency in meaning. The tools were pilot tested prior to fieldwork among adolescents of similar characteristics in a slum outside of the study area.

A total of 49 IDIs (23 in Viwandani and 26 in Korogocho) and 8 FGDs (4 in each site) were conducted. Participants were purposively-selected from households in the NUHDSS to include a mix of adolescents with different social demographic characteristics, including married and unmarried adolescents as well as adolescents who have ever been pregnant or impregnated someone. The research team worked with community health workers (CHWs) to recruit the respondents. The CHWs visited the households and introduced the study to the selected adolescents and their respective parents/guardians. Different groups of adolescents were interviewed for IDI and FGDs. The interviews were administered in Swahili by six trained and experienced male and female fieldworkers. Interviews were audio-recorded with the consent of the participants.

The socio-demographic characteristics of the participants in the study are presented in Table 2. Thirty of the $49 \mathrm{IDI}$ respondents had some secondary education, roughly half (25) of them were not in school at the time of the study. Majority (44 out of 49) of IDI respondents were not married. Thirty-five out of the 56 FGD participants were in school at the time of the study, 32 had some secondary education and 53 were not married. 
Table 2: Characteristics of IDI and FGD respondents

\begin{tabular}{|c|c|c|c|c|c|c|}
\hline & \multicolumn{3}{|c|}{ In-depth interviews } & \multicolumn{3}{|c|}{ Focus group discussions } \\
\hline & Female & Male & Total & Female & Male & Total \\
\hline & $n=27$ & $n=22$ & $\mathrm{~N}=49$ & $n=26$ & $n=30$ & $\mathrm{~N}=56$ \\
\hline \multicolumn{7}{|l|}{ Age } \\
\hline 15 & 3 & 1 & 4 & 6 & 4 & 10 \\
\hline 16 & 5 & 5 & 10 & 5 & 9 & 14 \\
\hline 17 & 5 & 4 & 9 & 6 & 3 & 9 \\
\hline 18 & 6 & 5 & 11 & 4 & 6 & 10 \\
\hline 19 & 8 & 7 & 15 & 5 & 8 & 13 \\
\hline \multicolumn{7}{|c|}{ Schooling status } \\
\hline In school & 9 & 15 & 24 & 15 & 6 & 21 \\
\hline Out of school & 18 & 7 & 25 & 11 & 24 & 35 \\
\hline \multicolumn{7}{|c|}{ Education level } \\
\hline Primary & 10 & 9 & 19 & 9 & 15 & 24 \\
\hline Secondary & 17 & 13 & 30 & 17 & 15 & 32 \\
\hline \multicolumn{7}{|l|}{ Marital status } \\
\hline Married & 5 & 0 & 5 & 1 & 2 & 3 \\
\hline Never married & 22 & 22 & 44 & 25 & 28 & 53 \\
\hline \multicolumn{7}{|l|}{ Residence } \\
\hline Korogocho & 16 & 10 & 26 & 15 & 16 & 31 \\
\hline Viwandani & 11 & 12 & 23 & 11 & 14 & 25 \\
\hline
\end{tabular}

\section{Data analysis}

Interviews were directly transcribed into English from Swahili. Data were coded using NVivo by the research team and a professional qualitative data coder, based on a jointlydeveloped codebook. The data were analyzed using a thematic approach. Key themes regarding causes and consequences of unintended pregnancy, contraceptive use, coping with unintended pregnancy, and abortion within the context of young people's lives in the slums were retrieved. Word-for-word quotations are presented to illustrate key issues and themes. 


\section{Ethical considerations}

Written informed consent was obtained from all interviewees for their participation and for the audio-recording of the interviews. For participants aged 15-18 years, interviewers sought consent from the parents or guardians before undertaking the interview (the Kenyan constitution considers married persons and those aged 18 years and above to be adults in their own right). These respondents were also requested to assent to participate in the survey and for the interview to be recorded. Interviews were conducted in private places to protect the confidentiality of responses and enhance the comfort of respondents. Interview sessions for IDIs lasted an average of 40 minutes, while the FDGs lasted 70 minutes on average. In this report, pseudonyms have been used to ensure the anonymity of respondents. This study received ethical approval from the Population Council's Institutional Review Board and the Kenya Medical Research Institute's Ethics Review Committee.

\section{Results}

\section{Narratives of socio-economic and health challenges}

The current study data suggest that adolescents faced a variety of socio-economic and health challenges in their communities. In both FGD and IDI sessions, adolescents described the insecurity, poverty, and uncertainties that characterize their everyday life. They noted that there were high-levels of crime, unemployment, and impoverishment in their communities. Respondents stated that many of them lived in poor and food-insecure households, where their needs for adequate food, decent clothing and respectable shelter were not always met. These challenges reportedly translated into low educational attainment, drug use, ill-health, and misery in the communities. Narratives firmly identified poverty as one of the major factors responsible for poor schooling outcomes and limited life opportunities among young slum dwellers. Adolescents stated that many young people do not complete basic schooling because of poverty and this leaves them poorly-equipped to transition successfully to secondary schools or secure good jobs. Illustrating this point, one young woman in the FGD among unmarried 17-19 year olds in Korogocho noted:

"...because of poverty, [parents can't] manage to get a good college for you so that you can get a job, and with the present Kenya...you can only get a job if you have gone to school..."

In the same FGD, another respondent noted:

"You know girls in the slums do not reach class eight. You can't learn when hungry and you can't work when you are hungry, you cannot read when you are hungry...And you can imagine yesterday you didn't eat supper, today we didn't eat lunch, which means in class you cannot concentrate...And this makes us leave school early." 
There was also 18-year-old Mercy who observed that:

"Because parents don't have money...young people do not go to school and become street children...They go to the dumpsites to collect items." (IDI participant, never married, Korogocho).

We also elicited poignant descriptions of the challenging implications of poverty for young people's social development. Young people in the slums reported that they were common victims of insecurity and violence including rape. The insecurity that characterized the lives of young people in Korogocho and Viwandani occurred at home and outside the home. Respondents observed that it was common for young people to be attacked on the streets, at school, while at play and in their homes. Common perpetrators of attack on young people included peers, teachers, parents, family members, adult neighbors, romantic partners and strangers. One respondent observed:

"You will find an adult man goes to have sex with a small girl whose breasts have not even come out....Because he will pretend to send a child to the shop go and buy for bread... He will even threaten you with a knife... so for a child she will feel terrified and the man will rape her. Even neighbors tend to rape children." (FGD 17-19 year old females, never married, Korogocho)

Sexually transmitted infections, including HIV were also reportedly common among young people in the two communities. Young respondents associated STIs, with general poor health, high mortality, poor schooling outcomes, and discrimination. Narratives associated poverty and consumerism with high-levels of poor sexual and reproductive health among young people in the slums. As illustrated in the quotes below, young girls were noted to rely on transactional sex for money, basic needs and needs related to consumerism (e.g. fast food or 'nice' clothes):

"You can find a girl who is 15 years in a relationship with a man who is 50 years or even 60 years not because she likes it, but because of money." (FGD 17-19 year old females, never married, Korogocho).

Another respondent also noted:

"Girls are usually lured with French fries, yoghurt and such like things... They feel when they go to the man's place she eats well...She feels things are better here and so when she is invited to have sex...She will not refuse..." (IDI participant, 19 year old male, Viwandani).

Our respondents further identified lack of sexuality information, peer pressure, sexual violence and low levels of education as key drivers of poor SRH among adolescents in the slums. The critical role of low educational levels as a driver of poor SRH among young people in the slums was explained thus by a 16 year-old male IDI respondent from Korogocho:

"If I am a girl and I haven't gone to school I don't have that ability to know that if I do this it is bad. So I will just engage myself in sex leading to unwanted pregnancies or dropping out of school." 
Poor parent-child communication was noted to impact on adolescent sexual behavior. One 17 year-old male IDI respondent from Korogocho noted that "...Parents should take time and talk with their children about how these things happen...And how they can prevent them." Similarly, parental death or absence, poor discipline and weak family ties were commonly described as reasons for risky sexual behavior, including early initiation of sexual activity among young girls and boys.

While young people were generally aware of the consequences of unprotected sexual activity and multiple partnerships, HIV-related knowledge was relatively poor. Many considered themselves not to be at risk, felt they had no need to go for VCT and did not express adequate knowledge of HIV transmission and prevention practices. One 19 yearold female IDI respondent from Viwandani noted:

"Most young people ... when you tell them to go for VCT, they are like; what? VCT? To do what? I am too young to get that disease. And so many people do not take their health seriously."

Data suggested that the types of sexual relationships among adolescents in the slums were varied and included same-sex relationships, sexual relationships with older adults, sex work, and romantic relationships with peers. There were also mentions of incestuous sexual relationships among young slum dwellers. In general, narratives suggested that most of the sexual relationships involving young people put them at risk of infections and unintended pregnancy because sexual activity often occurred in relationships in which adolescents had limited freedom to negotiate for safe sex and contraceptive use.

\section{Causes and consequences of unintended pregnancies}

Table 3 provides an illustrative summary of narratives on the causes and consequences of unintended pregnancies among adolescents in urban slums in Nairobi. Early and unintended pregnancies were reportedly common among girls in their communities. Narratives suggested that the first pregnancies for most young girls in the slums were unintended, often occurring when the girls were very young and unprepared for motherhood. Besides personal admissions of having become pregnant accidentally or making someone pregnant accidentally, several respondents also reported personal knowledge of girls in their community who had experienced an unintended pregnancy. In an FGD of 15-16 year-old females, a 16 year-old female in Korogocho noted that she got pregnant at 14 . Her boyfriend had convinced her to demonstrate her love for him by having unprotected sex with him. A 17 year old, unmarried female respondent from Korogocho recounted her own experience by saying: "I was not expecting... The boyfriend usually used a CD [condom]...I didn't know he had torn it." Another respondent highlighted her younger sister's experience stating:

"The moment she gave birth to that child she told me that she didn't know how the other child came...she was just surprised to discover that she is pregnant after one month." (IDI, 19 year old female, married, Viwandani). 
Table 3: Illustrative summary of narratives on the causes and consequences of unintended pregnancies among adolescents in urban slums in Nairobi

Causes

- Lack of self-control

- Low levels of contraceptive use or contraceptive failure

- Poor contraceptive knowledge

- Lack of access to reproductive health services, particularly youth friendly services

- Drug and alcohol use

- Poor parental support or parent-child communication on sexuality issues; dysfunctional families

- Peer influence including validation of manhood for boys

- High levels of poverty

\section{Consequences}

- School dropouts

- Financial difficulties and limited livelihood opportunities

- High levels of abortions, particularly unsafe abortion

- Poor health outcomes

- Strained relationships and abandonment

- Child neglect

- Psychological trauma and suicides

- Early marriages

- Commercial sexual activity or transactional sex

- Stigma

Study participants noted that girls who become pregnant often dropped out of school, terminated the pregnancies, were chased away from home by their parents, were abandoned by the men responsible for the pregnancies or were married off.

The causes of unintended pregnancies identified by the adolescents included early sexual activity, sexual violence, low education, ignorance and illiteracy, lack of access to contraceptives, partner opposition to contraceptive use, poverty, multiple sexual partnerships, transactional sex, and peer pressure. Narratives suggest that sexual activity often started at very early ages, when adolescents have little information about pregnancy prevention. Adolescents also noted that exposure to sex and sexually explicit materials occurred quite early in the slum areas, often prompting them into experimenting with sex at very early ages. Unintended pregnancy was also associated with moral laxity and irresponsibility among girls. Sexual violence and abuse by peers, parents and other adults, including teachers was also a common explanation of unintended pregnancy among adolescents. We elicited stories suggesting that teachers and male guardians were responsible for some of the unintended pregnancies experienced by young girls in the slums. Poverty also reportedly put girls at risk of risky survival sex, exposing them to unintended pregnancy as well as other negative health outcomes. As one respondent noted:

"And you know now, girls mostly get into the box (slang expression meaning to consent to sex) fast because obvious if I tell a girl that I have dough [money]... 
I know how I will feed you...if you have fallen into a relationship with a girl, you may force her if she has mostly been using your money... If your relationship started a long time ago and you have been giving her money.... So you know, the day you will ask for sex...She will...she will give you." (IDI participant, 18 year old male, never married, Korogocho).

Peer pressure also exposed adolescents to early sexual initiation and staying sexually active. In the data we collected, peer pressure especially for girls was often framed within the context of conformity and envy. John Eric for example stated:

"Some of their friends have boyfriends and so they want to be like them..." (IDI participant, 17 year old male, never married, Korogocho).

Mary-Jane, a 19 old never married female from Viwandani noted:

"My friend is pregnant and she is fine and why not me?"

For boys, masculinity was constituted in terms of sexual activity and number of sexual partners that one had. Boys without sexual partners or who did not show evidence of sexual activity were frequently treated disrespectfully by their peers. As John, a 19 year old student in Korogocho put it:

"You find the other [boys] telling you that you don't have a girlfriend... That you are not a man enough."

Respondents also associated unintended pregnancy with poor contraceptive practices among adolescents. Reportedly, contraceptives were inaccessible and unaffordable to adolescents. In other instances, adolescents lacked adequate knowledge of contraceptives. Stigma was also a barrier to the use of contraceptives among adolescents. As Nicholas, a 16 old year old, never married male in Korogocho noted:

"It is not easy for small [young] people like us to go to a pharmacy to ask for condoms or pills'..."

Respondents often talked of limited choices in methods that adolescents could use and had access to. Most often adolescents reported that choice of contraception was not based on expert opinions from service providers but rather on what their peers were using. Reports of contraceptive failure among adolescents were also common. Respondents noted that some adolescents used contraceptives inaccurately and inconsistently, which often resulted in unintended pregnancies. One respondent said:

"The girl didn't imagine that she could be pregnant because she was on Femiplan contraceptive...And she was not using it the way she had been instructed by the doctor....And so she became pregnant."(IDI participant, 17 year old male, never married, Viwandani)

Misconceptions about contraceptive use and perceived side effects had a negative impact on young people' willingness to use contraception. Highlighted side effects included reduced fertility, sterility and weight gain. Sheila aged 18 from Korogocho also said:

"...So condom also is risky if you use for a long time you can be infected with a 
disease, growth in the stomach, so we don't know which protection we will use? We don't know whether we just go for prayers?"

There was also Ann a 19 year-old participant in Korogocho who asserted that:

"[The condom] causes growth in the stomach, because of the oil inside it, so you are not supposed to use for a longer period of time. We are told that it is the best protection but we should not use it for long, and if you use pills for long is not also good, you can develop growth in your stomach". (FGD 17- 19 year old, separated, Korogocho)

Although unintended pregnancies were considered to be common among adolescents, they were associated with many poor social and health outcomes. The commonlymentioned implications of unintended pregnancies were early marriage, discontinuation of schooling, health complications, stigma, unsafe abortion, and even death. There were also stories suggesting that unintended pregnancies also result in rejection by the male partner, parental abandonment, loss of livelihood, prostitution to support child, and stigma.

\section{Coping with unintended pregnancies}

The adolescents we interviewed mentioned several ways unintended pregnancies were managed by their peers. A major strategy for coping with unintended pregnancies among adolescents in the slums was to drop out of school. Adolescents told us that unmarried in-school young girls who got pregnant would often discontinue schooling. It was reported that in some instances, school authorities would bar such girls from coming to school. But more commonly, stigma and shame would force pregnant adolescents to stay away from school. It was also noted that most parents usually discontinued support to girls who become pregnant forcing such girls to look for work to support themselves. Getting a girl pregnant also sometimes led boys to drop out school. Such boys would drop out of school in order to work to support the girl and new family. As Freddie, an 18 year old, never married male IDI participant in Korogocho put it:
"You have gotten a young girl pregnant and you were also schooling. You are at school...So you will just have to drop out of school and you know... These days in Kenya, you just have to have documents that show that you went to school... Thus he cannot go anywhere..."

In some instances, mistreatment and stigma by peers at school also forced such boys to drop out school. Data indicated that boys with pregnant girlfriends were regularly taunted and stigmatized at schools by peers. Parents of such boys would also often discontinue support to them.

A second common strategy for coping with unintended pregnancies was to seek an abortion. Although several respondents noted that there was a decline in reported abortion due to intervention programs, interview data suggested that abortion was commonly practiced in the community. The choice to have an abortion was reportedly influenced by fear of being stigmatized, the fear of parental reaction to the pregnancy, the desire to continue with formal education, and the perceived cost of taking care of the unborn child. 
Explaining how the cost of taking care of a child would lead a young woman to the decision to have an abortion, Elizabeth, a 19 year old unmarried female in Viwandani said:

"Money to buy a child's clothes or food, money to take the baby to hospital where will I get it? The best I can do is just have an abortion."

Adolescents told us that mostabortions were either self-induced or procured with assistance from traditional herbalists, and unskilled providers. Participants noted that adolescents obtained abortion services from doctors or skilled providers infrequently due to the high costs. Interview data suggested that many methods were used by adolescents to procure abortions. Methods mentioned varied and included taking an overdose of painkillers or other medicines; perforation of the cervix using sharp objects; use of traditional bitter herbs, and ingesting harmful substances such as bleach, detergents, and concentrated tea-leaves. Overall, the decision on which methods to use to terminate a pregnancy was influenced by several factors including cost, confidentiality, convenience, and peer influence. The efficiency and safety of abortion methods was also considered when choosing a method of abortion. Although some adolescents tended to choose methods perceived to be quick and readily available, others noted that safety was a consideration. Adolescents considering an abortion were reportedly more likely to confide in close friends particularly those who had procured an abortion themselves.

Another major strategy for managing unintended pregnancy was to carry the pregnancy to term. Some respondents noted that uncertainty, fear about the safety of abortion and the ability to afford the cost of an abortion were some of the determining factors that prompted some young girls to carry the unwanted pregnancy to term. Judith, a 19 old unmarried female from Viwandani noted:

"You find out from someone who has done it before, how much is it to have an abortion? She will tell you either Sh5, 000 or maybe Sh10, 000 and you are like where will I get all this money? Let me just stay like that and keep the pregnancy."

Many adolescent girls also decided to keep the pregnancy if there was parental resistance to abortion, parental willingness to provide financial support for the child, or assurances of marriage or financial support for the child from the father or another male partner. The decision to keep a pregnancy was also influenced by availability of external assistance, such as maternal health care vouchers. Narratives suggested that adolescent girls who decided to carry pregnancies to term faced financial difficulties in meeting the child's basic needs, which in some instances led some girls to resort to crime or commercial sex work.

In a few instances where unintended pregnancies were carried to full term, some girls eventually gave up the child for adoption or some extreme cases abandoned or even killed the child. In talking about adoption, Maryanne, an 18 year old, never married female from Korogocho said:

"let's say you are pregnant and you didn't abort the baby, but you gave birth... And since you want to go back to school... We have a charity home here... you can take the baby there and then you can you go back school..." 
For some girls, however, an unintended pregnancy led to suicide. Jane, who reportedly knew a young girl who committed suicide, stated:

"She decides to go and commit suicide because when she goes to tell the mother that will be a different story, she will be chased away, she goes to tell the boy and he deserts her and so she decides to go and commit suicide." (IDI participant, 16 year old female, never married, Viwandani)

Gender differences were noted in the coping strategies employed to deal with unintended pregnancies. For girls, the initial response to the realization of an unintended pregnancy often involved regret, anger, embarrassment, resignation and then acceptance. Even in acceptance of a pregnancy, narratives from the adolescent girls noted that some girls would resort to hiding during pregnancy because of shame and embarrassment. Valentine a 15 year old, never married male IDI participant from Korogocho noted:

“...she feels ashamed and doesn't want come out, for example...So, maybe she wants to stay with the pregnancy until nine months are over and then she will... She will start to come outside once she gives birth..."

In all, a girl's decision on how to manage an unintended pregnancy was strongly influenced by the actual or perceived response of parents and male partner.

For boys, the coping strategy depended on whether he accepted or denied responsibility for the pregnancy. In some instances, an unintended pregnancy was positively viewed as a confirmation of the boy's "manhood" as noted by Bernard, a 19 year old, unmarried male from Viwandani:

"Of course he will feel proud to be called a man...I now have my photocopy and something like that. He feels that he can now prove that he is a real man."

In situations where boys took responsibility for a pregnancy, they found ways to get money to support the child and the mother. Some boys resorted to crime, seeking employment, or leaving the child with his parents. Acceptability of pregnancy did not always involve cohabitation or marriage between partners, but rather in certain cases boys assisted the girl while still at her parents' home. Marriage was not always a voluntary decision and some boys were forced (usually by the girl's parents) to take that step.

In certain cases, males' responses to unintended pregnancies were denial, ambivalence, lack of concern, relocation, aggression toward the female partner, and insistence on an abortion. Denial of responsibility for the pregnancy sometimes was due to embarrassment from ridicule which could be heaped on him by his peers. In other cases, denial was attributed to the boy's age, unpreparedness for the responsibility of taking care of a family, and the existence of another female partner. In some cases, however, denial stemmed from suspicion that the girl had multiple partners and therefore could not be trusted. As one respondent in an FGD with 15-17 year old males in Viwandani noted:

"How will I know that it is mine and maybe she has been doing sex with many people? Ladies cannot be trusted." 


\section{Strategies to prevent unintended pregnancies}

At the individual level, adolescents believed that behavior change was necessary to prevent unwanted pregnancies. Many noted that girls could avoid unintended pregnancies through abstinence and self-control. Narratives of the importance of abstinence were occasionally couched in the belief that any encouragement of contraceptive use would encourage risky sexual behaviors among adolescent girls or that the use of contraception was for adults with children. With respect to the former, one respondent during an FGD among girls aged 17-19 years in Viwandani said, "...No. Telling girls to use family planning is telling them to continue being prostitutes." However, some respondents felt that contraceptive use was a viable alternative in cases were abstinence was unattainable.

Some participants also noted that avoiding bad company including relationships with boys and 'bad' friends who would negatively influence their behavior was another strategy to prevent pregnancies among adolescents. Adolescents stated that many adolescents engaged in sexual activity because they were idle. They therefore suggested that unintended pregnancies could be avoided if adolescents kept busy by participating in after-school or other civic activities, attending seminars or pursuing training opportunities. Repeated stories from adolescents pointed to the fact that poverty was the main cause of risky behaviors that led to unwanted pregnancies. Poverty not only caused young women to turn to men to be able afford basic necessities, but joblessness resulted in idleness leading many adolescents to engage in risky sexual behaviors. They therefore suggested that job and wealth creation were important mechanisms by which early unintended pregnancies could be prevented. Job creation was noted to have more of an impact on behavior change that could directly or indirectly reduce unintended pregnancies than interventions or seminars that encourage contraceptive use or abstinence. This argument is highlighted in the following quote:

"...When you come with the subject of family planning don't bring us those stories of condoms and abstaining, it won't work, we have heard those things from long time ago and there are those who listen and adhere while others don't really care. It just doesn't make sense anymore but if you are kept busy and earning, then you will be in a better place not to engage in some these things." (FGD, males, 17-19, Viwandani)

At community level, respondents noted that schools, faith-based organizations, and parents should encourage and advise adolescents to abstain from sexual activity. In particular, parental advice, guidance, communication and involvement in the adolescent's life were identified as key to helping adolescents avoid risky sexual behaviors that would put them at risk of experiencing an unintended pregnancy. Respondents also identified the need for community centers that provide guidance and counseling, educational forums and weekly seminars on contraceptive use, sexuality and general life skills as preventative strategies. Ann, an 18 year old, never married female from Korogocho noted that:

"First is education on sexuality, people need that education...They didn't know that when you do this and that you will get pregnant and it would be good if the knowledge is imparted to the people especially the teens." 
Media was highlighted as a powerful teaching and outreach tool that could be used to educate adolescents through programs such as movies, documentaries, debates on issues surrounding adolescence.

The role of government was also highlighted. Respondents noted that government could tackle the issue of high school drop out by assisting individuals who drop out of school due to financial constraints to re-enroll and continue their education. Respondents also noted that the government should put in place systems to enable girls who dropped out as a result of an unwanted pregnancy re-enroll once they already had the baby. Furthermore, it was argued that the insufficient number of schools in the study communities contributed to risky behavior among adolescents and so the government should take it upon itself to build more schools. Adolescents also noted that perceived high levels of rape in the studied communities need to be tackled by the government through penalizing and prosecuting rapists. Finally, as illustrated in the quote below, participants also underscored the importance of improved access to youth friendly reproductive health services where adolescents could easily access quality and confidential services:

"They can set up centers like VCT where you can access them without asking for them or somebody knowing what you have gone there to do." (FGD, males, 15-17 years, Viwandani)

\section{Discussion}

Young people growing up in urban slums live in challenging situations characterized by limited educational and livelihood opportunities. Young people in Kenyan slums are at high risk for unintended pregnancies and associated poor sexual and reproductive health outcomes. It is estimated that $49 \%$ of pregnancies among $15-19$ year olds in Nairobi's slums are unintended [12]. The experience of unintended pregnancies exacerbates the already challenging life situation with severe consequences for both boys and girls. For young people in urban slums, the prevention of early and unintended pregnancies is therefore imperative. This qualitative study examined the challenges faced by adolescents with regards to unintended pregnancies and how adolescents in urban slum settlements manage and cope with unintended pregnancies. The overall expectations are that the findings will inform the design of sexual and reproductive health intervention programs that respond to the unique needs of adolescent boys and girls living in resource-poor urban settings.

Our findings suggest that high levels of unintended pregnancy among young people in Kenya's urban slums are linked to myths and misconceptions about contraception. Repeated accounts indicate that many youth rely on information from peers rather than health professionals. Young people's misconceptions also act as a significant barrier to contraceptive use. Efforts to reduce unintended pregnancies among young people in urban slums must therefore include reproductive health education programs that debunk the myths and misconceptions that young people have about contraceptive methods. Similarly, expanding contraceptive method choices beyond the pill and condoms is essential. This can be achieved by enhancing existing service provision channels to provide accurate information and services on a wide range of methods including long-acting and reversible methods to capture the diverse needs of this group 
Moreover, targeting girls early in their adolescence with SRH information and services is imperative as our study findings show that many young girls had their first pregnancy at very early ages. Reaching young girls in their early adolescence, especially before they initiate sexual intercourse, with well-designed comprehensive sexuality education will have significant impact on preventing adverse SRH outcomes, such as early unintended pregnancy and unsafe abortion. Comprehensive sexuality education that provides culturally relevant, accurate and age-appropriate information about sex and relationships during early adolescence has been shown to equip young girls with positive values and attitudes and promote positive behavior change such as delaying sexual debut or negotiating safe sex [14].

Study findings underscore the fact that many young people lack access to contraception and reproductive health services. Provision of youth friendly reproductive health services is one of the commitments made by the Kenyan government during the 2012 Family Planning Summit in London [15]. Achieving this goal requires innovative and cost-effective approaches. As highlighted by Erulkar et al. [16] a cost-effective way to ensure quality youth-friendly services is to improve the clinical aspects of current reproductive health services to meet the needs of young people through internal re-organization especially staff training and through outreach activities that take the services to young people both in and out of school. A comprehensive mapping and evaluation of existing sexual and reproductive health services is also critical.

The findings from the formative study indicate that unintended pregnancies are linked to sexual violence. Previous studies have shown that girls who are exposed to violence are more likely to experience an unintended pregnancy [17]. Girls with no safety nets or social support are more vulnerable to forced or coerced sex than girls with more social support and access to safe spaces [18]. As proposed by other studies on other slum settlements in Kenya [19], creation of safety nets, addressing personal security and social support remain imperative to addressing key challenges - including unintended pregnancies - faced by adolescents in urban poor slum settlements. In addition, community-level violence prevention interventions, including those that focus on changing male attitudes towards violence towards women and girls are critical.

Discussions with young people highlighted the need for government to manage the high levels of school dropout as a result of an unintended pregnancy, by implementing programs that not only facilitate young people (especially young girls) to re-enroll in schools and continue their education after a pregnancy, but also provide financial subsidy to retain girls in school. The Kenyan government has over the last two decades put several strategies in place to reach disadvantaged adolescents such as the Free Secondary Education Policy (FSE) to allow more children access and attain basic secondary education and reduce the financial burdens on families and the Educational Re-entry policy for girls after teenage pregnancy [20]. Specifically, to increase the participation of disadvantaged girls in education, Kenya in 1994 through its Ministry of Education (MOE) introduced a new policy that would support teenage mothers to continue schooling after delivery [20]. In 2003, this policy was reviewed to better ease re-admission of girls while still in school and provide more opportunities for these girls to attend a different school to avoid being stigmatized. According to a study conducted by the Forum for African Women Educationalists (FAWE), 
in 2001 many girls still fail to attend school after delivery, while another study in 2008 showed that about 13,000 girls leave school each year in Kenya due to pregnancy [3]. The extent to which young girls are taking advantage of this policy, awareness of the policy by school officials, and challenges in the implementation of the policy remain unclear, especially in disadvantaged areas such as the slums [20]. There is therefore the need to sensitize slum dwellers and key stakeholders on the Education Re-entry policy for pregnant girls, so they can take advantage of opportunities to complete their education.

Study findings suggest that structural factors, especially poverty, may play a key role in driving risky sexual behavior and its consequences, including early unintended pregnancies. The narratives showed that for young people, transactional sex, which was often unprotected, was driven by inadequate access to basic amenities, including food and menstrual regulation products. The findings suggest that multi-pronged approaches that enhance access to schooling, and which include job and wealth creation may have a more direct and sustainable impact on reducing risky sexual behaviors and, ultimately, unintended pregnancies among adolescents in urban slums. Indeed, adolescents were most likely to reflect on the seemingly little impact of interventions that only emphasized behavior change and especially regarding contraceptive use.

\section{Programmatic Implications}

Programs to reduce unintended pregnancies among young people in urban slums should:

- Provide reproductive health information that debunk the myths and misconceptions that young people have about contraceptive methods.

- Ensure quality youth-friendly services by improving the clinical aspects of current reproductive health services to meet the needs of young people in and out of school. A comprehensive mapping and evaluation of existing sexual and reproductive health services will be an essential part of the process.

- Enhance existing service provision channels to provide accurate information and services on a wide range of methods including long-acting and reversible methods to capture the diverse needs young people.

- Ensure the provision of comprehensive sexuality education, especially at early adolescence that equips young girls with culturally relevant, accurate and ageappropriate information about sex and relationships.

- Create safety nets and address personal security and social support needs of adolescents in urban poor settlements.

- Focus on changing male attitudes towards violence against women and girls.

- Sensitize slum dwellers on the Education Re-entry policy for pregnant girls.

- Adopt multipronged approaches that enhance access to schooling and increase livelihood opportunities. 


\section{References}

1. Kenya National Bureau of Statistics (KNBS) (2010) Kenya Demographic and Health Survey 2008-09: Calverton, Maryland: KNBS and ICF Macro.

2. Obare F, Birungi H, Undie C, Wanjiru M, Liambila W, et al. (2011) Levels, trends and determinants of contraceptive use among adolescent girls in Kenya: APHIA II OR Project in Kenya. Nairobi, Kenya: Population Council.

3. Muganda-Onyando Rosemarie, Omondi M (2008) Down the Drain: Counting the Cost of Teenage Pregnancy and School Dropout in Kenya. Center for the Study of Adolescence www.csakenya.org.

4. Ministry of Medical Services (2012) Standards and guidelines for reducing morbidity \& mortality from unsafe abortion in Kenya. Nairobi, Kenya: Ministry of Medical Services.

5. African Population and Health Research Center (APHRC), Ministry of Health (MOH), Ipas, Guttmacher Institute (2013) Incidence and complications of unsafe abortions in Kenya: Key findings of a national study. Nairobi, Kenya: APHRC, MOH, Ipas, Guttmacher Institute.

6. Kenya Human Rights Commission, Reproductive Health and Rights Alliance (2010) Teenage Pregnancy and Unsafe Abortion: The Case of Korogocho Slums. Nairobi, Kenya: Kenya Human Rights Commission.

7. African Population and Health Research Center (2002) Population and Health Dynamics in Nairobi's Informal Settlements: Report of the Nairobi Cross-sectional Slums Survey (NCSS) 2000. Nairobi, Kenya: African Population and Health Research Center.

8. Beguy D, Mumah J, Wawire S, Gottschalk L, Kabiru C (2013) Status Report on the Sexual and Reproductive Health of Youth Living in Urban Slums in Kenya. STEP UP Techinical Working Paper Nairobi, Kenya: African Population and Health Research Center.

9. Zulu EM, Dodoo FN, Ezeh AC (2002) Sexual risk-taking in the slums of Nairobi, Kenya, 1993-98. Population studies 56: 311-323.

10. Kabiru CW, Beguy D, Undie C-C, Zulu EM, Ezeh AC (2010) Transition into first sex among adolescents in slum and non-slum communities in Nairobi, Kenya. Journal of Youth Studies 13: 453-471.

11. Department for International Development (DFID) (2010) Improving Reproductive, Maternal and New born Health: Reducing Unwanted Pregnancies. Evidence Overview (Working Paper: Version 1.0).

12. African Population and Health Research Center (2014) Nairobi Cross Sectional Slum Survey (NCSS) II: Report on Demographic Behavior, Health Outcomes and Livelihoods Conditions of the Urban Poor in Nairobi Informal Settlements [Unpublished Report]. Nairobi, Kenya: African Population and Health Research Center.

13. Kabiru CW, Mojola SA, Beguy D, Okigbo C (2013) Growing Up at the "Margins": Concerns, Aspirations, and Expectations of Young People Living in Nairobi's Slums. Journal of Research on Adolescence 23: 81-94. 
14. Ringheim K, Gribble J (2010) Improving the reproductive health of sub-Saharan Africa's youth: Washington, DC: Population Reference Bureau. http://www.prb.org/ Reports/2010/youthchartbook. aspx.

15. London Summit on Family Planning (08 May 2013) Summaries of Country Commitments.

16. ErulkarAS, Onoka CJ, Phiri A (2005) What Is Youth-Friendly? Adolescents' Preferences for Reproductive Health Services in Kenya and Zimbabwe. African Journal of Reproductive Health / La Revue Africaine de la Santé Reproductive 9: 51-58.

17. Miller E, Levenson R, Herrera L, Kurek L, Stofflet M, et al. (2012) Exposure to partner, family, and community violence: gang-affiliated Latina women and risk of unintended pregnancy. J Urban Health 89: 74-86.

18. Erulkar A, Ferede A (2009) Social exclusion and early or unwanted sexual initiation among poor urban females in Ethiopia. International Perspectives on Sexual \& Reproductive Health 35.

19. Erulkar A, Matheka JK (2007) Adolescence in the Kibera slums of Nairobi, Kenya. Nairobi and New York: Population Council.

20. Omwancha KM (2012) The implementation of an educational re-entry policy for girls after teenage pregnancy: A case study of public secondary schools in the Kuria District, Kenya. Wellington, New Zealand: Victoria University of Wellington. 



\section{www.stepup.popcouncil.org}

The STEP UP (Strengthening Evidence for Programming on Unintended Pregnancy) Research Programme Consortium generates policy-relevant research to promote an evidencebased approach for improving access to family planning and safe abortion. STEP UP focuses its activities in five countries: Bangladesh, Ghana, India, Kenya, and Senegal.

STEP UP is coordinated by the Population Council in partnership with the African Population and Health Research Center; icddr-b; the London School of Hygiene and Tropical Medicine; Marie Stopes International; and Partners in Population and Development. STEP UP is funded by UK aid from the UK Government. 